\section{MEDICALLY ATTENDED INJURIES AMONG CHILDREN - SOME RESULTS FROM ALBANIA}

1,2 ${ }^{\text {Gentiana Qirjako, }}{ }^{2}$ Engjëll Mihali, ${ }^{2}$ Rudina Çumashi. ${ }^{1}$ University of Medicine, Faculty of Public Health, Albania; ${ }^{2}$ Institute of Public Health, Albania

\subsection{6/injuryprev-2016-042156.721}

Background Injuries are a leading cause of death and disability in children. The majority of these deaths occur in low- and middle-income countries and disproportionately on children from the most disadvantaged groups.

Methods During April - May 2014, the Health Behaviour in School Aged Children (HBSC) study was conducted in Albania, including a representative sample of 4898 school children (2507 girls and 2391 boys) aged 11, 13 and 15 years. The data were collected through self-completion questionnaires administered in the classroom.

Results $35 \%$ of the children 11, 13, 15 years reported that during the past year they have been injured at least once, in such a manner that they needed medical intervention. Of these, $11 \%$ have required serious medical interventions up to hospitalisation. Home surroundings (11\%), sport facilities (8\%), school (6\%) and streets $(4 \%)$ are the most frequent environments for the occurrence of injuries among children. About 14\% of the children have been injured during sport exercises, whereas $7 \%$ of the them have been injured while walking in the street. In all cases, boys have been substantially more injured compared with the girls.

Conclusions Our findings indicate the urgent need for improving the environment where children are involved, for being safe and free from injury. Informing interventions to prevent and reduce injuries among children should be a priority of public health as well as, programmes for child health should give priority to preventing and controlling child injuries in Albania.

\section{Violence}

\section{Post Tue 2.11}

\section{PATIENTS' AND FAMILY MEMBERS' INVOLVEMENT IN MANAGEMENT OF VIOLENCE IN MENTAL HEALTH CARE}

${ }^{1}$ Tella Lantta, ${ }^{2}$ Raija Kontio, ${ }^{1}$ Minna Anttila, ${ }^{1}$ Kaisa Kauppi, ${ }^{1,3}$ Maritta Välimäki. ${ }^{1}$ Department of Nursing Science, University of Turku, Finland; ${ }^{2}$ Hospital District of Helsinki and Uusimaa, Helsinki University Hospital, Finland; ${ }^{3}$ Turku University Hospital, Finland

\subsection{6/injuryprev-2016-042156.722}

Background Patient violence in mental health care is a widely recognised hazard for staff members. It causes burden also for the patients and their family members. In recent years, patients and their family members have been encouraged to take a more active role in the planning and delivery of health care. Therefore it is important to involve these groups also to development of novel methods for preventing and managing violence in psychiatric care.

Methods Four focus group interviews were conducted among members $(n=9)$ of mental health patients' association and members $(n=8)$ of associations for families of mental health patients. This study aimed to explore participants' ideas how to prevent and manage patient violence in psychiatric care. The data collection took place in Finland, during August and October 2012. Inductive content analysis was used.
Results From the patients' and family members' viewpoints', meaningful activities to be organised for users' of psychiatric services were seen as an essential part of violence prevention. Humane nursing style and empathetic interaction was one of the key elements from participants' point of view in order to achieve non-violent and safe treatment environment. In addition, family members demanded possibilities to participate more actively to patient's treatment, receive up-to-date information and support from professionals of the mental health care. This could help them to participate in the demanding task of violence prevention and management.

Conclusions Both the patients and the family members suggested concrete ideas how to prevent and manage patient violence in psychiatric care. In the future, violence-related prevention and management programs in psychiatric care should include beside perspectives of the mental health professionals, also perspectives and heard voices of the patients' and their family members.

\section{HONOUR BASED VIOLENCE AND WELLBEING OF WOMEN AND GIRLS OF PAKISTANI HERITAGE IN SOUTH YORKSHIRE}

A Cronin de Chavez, S Bhanbhro, A Lusambili. Sheffield Hallam University

\subsection{6/injuryprev-2016-042156.723}

Background Honour Based Violence (HBV), a sub-category of gender based violence, is increasing in the UK and has a significant impact on well-being, particularly for women and girls. In the Independent Inquiry into Child Sexual Exploitation: 19972013 in Rotherham, South Yorkshire the 1,400 victims were reported to be mostly white British girls and the perpetrators mostly South Asian men. It is believed however there were also a number of unreported South Asian victims and that cultural sensitivity was prioritised over the wellbeing of girls subject to abuse in raising awareness of the problem for both ethnic groups.

Methods Mixed method study incorporating a) A literature review on HBV and wellbeing links; b) interviews ( $n=16)$, Focus groups $(n=4)$, with women and girls of Pakistani origin in Rotherham and Sheffield and WEMWBS wellbeing scale $(n=40)$.

Results This study explores the relationship between HBV and wellbeing of women and girls in Rotherham and Sheffield whilst employing culturally sensitive methodologies. The results of the literature review are presented regarding evidence for and against the role of equality and diversity dimensions, such as ethnicity, disability, gender, age and sexuality in HBV. Risk and protective factors and the evidence around any causal links between health (public and individual) and HBV are also presented. The results of the qualitative interviews identify where HBV may have been experienced in these two locations, what women and girls perceive to be HBV and how they believe their health and wellbeing is affected.

Conclusions Understanding of women and girls experience of HBV in Pakistani community by looking at socio-economic, political, individual, cultural and religious factors could be used as a pilot study for a larger, future study on prevention HBV in the UK. A greater understanding of the root causes of HBV could reduce the stereotyping of $\mathrm{HBV}$ being a purely cultural phenomenon. 